\title{
Checklist Completer
}

National Cancer Institute

\section{Source}

National Cancer Institute. Checklist Completer. NCI Thesaurus. Code C51809.

A person that is responsible for the completion of forms that contain a list of information regarding procedure or content validation. 